\title{
Assessment of Types of Dating Violence and Gender Prompting Involved in Dating Violence Among Undergraduate Students of University of Maiduguri
}

\author{
Nuhu Robert Kirtani ${ }^{1}$, Bulus Tikon ${ }^{2}$, Nashion Hananiah Likki ${ }^{3}$ \\ Department of Physical and Health Education, University of Maiduguri, Maiduguri, Borno State, Nigeria \\ Email address: \\ kirtani83@yahoo.com (N. R. Kirtani) \\ To cite this article: \\ Nuhu Robert Kirtani, Bulus Tikon, Nashion Hananiah Likki. Assessment of Types of Dating Violence and Gender Prompting Involved in \\ Dating Violence Among Undergraduate Students of University of Maiduguri. Education Journal. Vol. 8, No. 2, 2019, pp. 46-56. \\ doi: $10.11648 /$ j.edu. 20190802.12
}

Received: January 12, 2019; Accepted: March 7, 2019; Published: April 9, 2019

\begin{abstract}
The study assessed types of dating violence and gender prompting involved in dating violence among undergraduate students of university of Maiduguri, Borno state, Nigeria. Dating violence is a serious and prevalent public health problem that is associated with numerous negative physical and psychological health outcomes. There is limited research on prevention and intervention strategies to address the issue of dating violence. The development and evaluation of evidence-based programs targeted at dating violence prevention is very important. The study used a descriptive research design. Three hundred and eighty-four (384) copies of questionnaires were administered but three hundred and fifty-six (356) copies were retrieved, making $93 \%$ return rate. The analysis of the data collected was done using descriptive statistics (charts, frequency counts and percentages). The result of the study revealed that emotional abuse, psychological abuse, physical abuse and controlling behavior were the types of dating violence in the study area. Ridiculing or insulting women/men as a group, mocking women/men in general, believes that the opposite sex is inferior, making fun of one or discredit one as a women/man and unjustly, criticizing one sexuality by one's friends were the gender prompting involved in dating violence among undergraduate students of university of Maiduguri Borno State. The researchers recommended that safe date's program should be added to preexisting curriculum to educate undergraduate students about the effect of dating violence.
\end{abstract}

Keywords: Gender, Dating Violence, Undergraduate Students

\section{Introduction}

Dating violence (DV) among college students is a pervasive problem that has far reaching consequences on society, with up to $22 \%$ of college students estimated to be victims of dating violence each year [59]. Dating is defined as a relationship in which two individuals share an emotional, romantic, and/or sexual connection beyond a platonic friendship, but are not married, engaged, or in a similarly committed relationship [54]. The definition of DV (and/or dating abuse) is the use of physical force, or the threat of physical force or restraint, within a dating relationship [62]. In more recent years, the scope of dating violence has been broadened to include psychological abuse defined as verbal assaults between partners or from one partner to another (demeaning, degrading, or derogatory verbal terms) and sexual abuse that includes, but is not limited to, sexual coercion, rape, and molestation [19].

Violence on the other hand is the intentional use of force (physical, psychological, verbal, etc.) or power which may be threat or actual, against oneself, another person or against a group of persons/community that either results in or has the likelihood of resulting in injury, psychological harm, maldevelopment or deprivation [9]. Violence includes any condition or act that creates a climate in which the individual feels fear or intimidation in addition to being a victim of assault, theft or vandalism [8].

Youth are in a developmental period when courtship behavior is first initiated and the risk of abuse by a partner first emerges. The transition from childhood to adulthood leads to rapid change in behavior and strong emotions, changes such as having an intimate or close relationship with 
the opposite sex. Many youth enter into dating relationship without prior experience. So social media effect, lack of self concept and bad parenting style are some of the challenges faced by youth. According to [1], maintaining a healthy relationship require skills that many adolescents are not patient enough to learn. The lack of conflict handling skills and growing up in environments that experience constant violence or in communities that experience high rates of violence, can lead to unhealthy and even violent relationships among adolescents [1].

The following Socio-cognitive variables are examined visa-verse, the dating violence among undergraduate and college students in global and local settings. Globally, Intimate Partner Violence (IPV) is recognized as a major public health problem that violates the fundamental human rights. The World Health Organization defines IPV as 'behaviour within an intimate relationship that causes physical, sexual or psychological harm including acts of physical aggression, sexual coercion, and psychological abuses that controls behaviour. IPV can take several forms including physical violence such as pushing, shoving, slapping, punching, burning, use of a weapon, sexual including coercion and psychological violence leading to acts of humiliation, intimidation, and other controlling behaviours. IPV occurs in both low and high income countries and about one in three women worldwide are reported to experience IPV at some point in her life [20].

The WHO multi-country study found that the reported life time prevalence of IPV varied from $15 \%$ to $71 \%$ with the highest prevalence found in rural Ethiopia suffer detachment and humiliation, coercion, emotional punishment in their dating relationships. There are several theories about the causes and consequences of IPV against women. The risk factors that influence the occurrence of IPV which are classified as individual, relationship, community and societal level factors. These factors include young age, lower educational status, and unemployment, harmful use of alcohol and witnessing of parental violence, relationship quality and having multiple partners, poverty, and discriminatory societal gender norms. Nigeria currently has one of the highest populations on the Africa continent. The country is heterogeneous in composition, with wide geographical, cultural and ethnic diversity. The failure to domesticate the United Nations report on the Convention of Elimination of all forms of Discrimination Against Women (CEDAW) in spite of Nigeria being a signatory has been a lingering problem. Nigeria is a male dominated society where men are assigned more economic and political power and women are more dependent and this situation increases the risk of dating violence [40].

Physical aggression, which may include grabbing, slapping, and punching one's partner, occurs in approximately $20-37 \%$ of all dating relationships. Aggression, the most common form of violence that occurs between dating partners, includes verbal insults, threats, and degrading remarks, is estimated to transpire in $60-90 \%$ of dating relationships. Lastly, sexual aggression, which includes forcing unwanted sexual activities upon one's partner, occurs in approximately $2-14 \%$ of dating relationships. Additionally, it is not uncommon for individuals to experience more than one form of aggression [43]. There is also evidence to suggest that males and females perpetrate similar amounts of physical and psychological aggression against their dating partners with males routinely perpetrating more sexual aggression. Additionally, research has indicated that violence among adolescents and young adults in dating relationships can lead to severe violence later in life, such as in marital relationships. Therefore, it is clear that dating violence evidences itself in numerous topographies and affects a significant proportion of adolescents and young adults. Research consistently demonstrates that individuals experiencing dating violence evidence a number of adverse psychological and physical outcomes. The psychological correlates of dating violence are numerous, with victims experiencing mental health problems that include depression, posttraumatic stress disorder, anxiety, increased substance abuse, and low self-esteem [5]. Further, victims of dating violence often report injuries, such as facial and head trauma, and chronic gastrointestinal conditions. Lastly, it is not unheard of for homicide to result from these destructive relationships. In light of the prevalence of dating violence and its harmful correlates, there exists an urgent need for a thorough understanding of how these violent relationships operate. Students experience the same types of abuse in relationships as adults. This can include: Physical abuse - any intentional use of physical force with the intent to cause fear or injury, for example hitting, shoving, biting, restraining, kicking, strangling, or use of a weapon. Emotional /psychological abuse - non-physical behaviors such as threats, insults, constant monitoring, humiliation, intimidation, isolation, or stalking. Sexual abuse - any action that impacts a person's ability to control whether or not sexual activity occurs [29].

There are many forms of sexual abuse or assault, but at its basic, sexual assault is any form of unwanted sexual contact obtained without consent or through the use of force, threat of force, intimidation or coercion. A few examples of those forms may include: physically forcing a sexual act on another person, making a sexual partner feel guilty for not having sex until she "gives in.", continually begging for sexual interaction or wearing the person down until she agrees through coercion, forcing a partner to "make love" after a physical assault and taking a partner perform a sex act that she does not want to do [24].

Despite the fact that women constitute half of the population, political appointments for women still fall short of the recommended $35 \%$ by the Beijing declaration. The early socialization process is also responsible for the entrenchment of certain norms and discriminatory gender specific codes of behaviour that have made women inferior than men. The national literacy rate for females is only $56 \%$, compared to $72 \%$ for males and in certain states especially the northern states, the female literacy, enrolment and 
achievement rates are much lower. In studies conducted on DV in Nigeria, a prevalence of $28.2 \%$ to $47.3 \%$ for physical violence and $12.5 \%$ to $21.5 \%$ for lifetime prevalence of sexual violence has been reported.

In urban Pakistan, a lifetime prevalence of 57.6\%, 54.5\% and $83.6 \%$ was obtained for physical, sexual indulgence, coercion, gender based phenomenon and instrumental violence respectively. The problem with learning to detach emotionally from emotional trauma is that when we are in healthy relationships, that mistrust stays and at the slightest hint of hurt or rejection, a person with emotional detachment disorder will withdraw and become cold and unavailable for communication and sharing of feelings. This can interfere with healthy relationships [7].

Research conducted in South Africa reports different prevalence rates for dating violence, due to methodological and definitional differences. These authors indicate, however, that the phenomenon is widespread in the country. The level of dating violence perpetration among school-going adolescents in Cape Town was found to be $40 \%$. Their findings were corroborated by a similar study, which found a prevalence rate of dating violence perpetration of $20.7 \%$ among school going adolescents in Cape Town [24]. The issue of dating violence is a particularly important one because of its association with the onset of sexual activity and consequently with STIs, including HIV. In a study conducted in KwaZulu Natal, South Africa, more than one third of girls aged between 15 and 19 reported that they had lost their virginity through force, coercion or trickery10. A related study of school-going adolescents in South Africa indicates that early onset of first sexual intercourse was more likely among males than females, and among older students and students of a lower socio-economic status [41].

Intimate relationship violence has detrimental effects on the victims' physical and mental health. Physical violence from intimate partner violence (IPV) could lead to traumatic brain injuries, which increase risks of enduring negative complications such as residual scar tissue in the brain, memory loss, psychological scarring, and fatalities, amongst other consequences [11]. Victims of violent intimate relationships have increased risks of poor mental health outcomes such as increased anxiety, higher rates of depressive symptomology, reduced self-esteem, and higher perceived stress [34]. In addition, increased concerns of poor health outcomes, substance abuse, and development of chronic illnesses were found to be associated with survivors of IPV [34].

The varying nature of romantic relationships (casual dating, in a committed relationship, cohabiting, married, etc.) in a college student sample may make it difficult to clearly delineate between violence between dating couples (DV), and violence between long-term or married couples (IPV). Current studies focused on studying intimate relationship violence (DV) with college students who also identified as emerging adults, as it is hypothesized that most college students are in casual dating relationships, or in the beginning stages of committed relationships. Moreover, it is important that research address the issue of DV among college students, as violent behavioral patterns in current intimate relationships may become enduring features in future romantic relationships [50-59].

\subsection{Statement of the Problem}

Ideally dating supposed to be mutual, cordial, kind, friendly with exchange of gifts and certain duties and obligations, ante nuptial relationship between opposite sex youths. Culturally, dating is meant to be devoid of violence and full of social interactions. It is a means of bringing loved ones together and forming a lasting bond or relationships in diversity.

It has been observed that dating has departed from the above scenario. In recent times there have been cuprous reports, on the media, print electronic and social indicating dating violence among youth in colleges, universities and institutions of higher learning. In general, these violence take different forms, for examples physical violence, it includes a wide spectrum of activities such as scratching, slapping, pushing, slamming or holding someone against a wall, biting, choking, burning, raping, beating someone up, and assault with a weapon. Psychological, emotional, verbal abuse just like physical abuse encompasses a broad array of behaviours on dating violence. Such abuses may include insulting, criticizing, humiliating in front of friends. This paper is designed to examine the relationship between detachment and dating violence among undergraduate students of university of Maiduguri.

\subsection{Objective of the Study}

i. To determine the types of dating violence among undergraduate students of university of Maiduguri Borno state.

ii. To determine the gender prompting involved in dating violence among undergraduate students of university of Maiduguri Borno state.

\subsection{Research Questions}

The following research questions were answered

i. What are the types of dating violence?

ii. What is the gender prompting involved in dating violence?

\section{Review of Related Literature and Empirical Review}

\subsection{Types of Dating Violence}

Focus is usually on four types of adolescent dating violence and abuse: cyber abuse, physical violence, psychological abuse, and sexual coercion. Physical dating violence includes a wide spectrum of activities such as scratching, slapping, pushing, slamming or holding someone against a wall, biting, choking, burning, beating someone up, and assault with a weapon [31]. Such violence obviously 
manifests itself with degrees of seriousness. Youth dating violence is believed to emerge between ages 15 and 16 . Paradoxically, many adolescents do not necessarily view such behavior as unilaterally destructive at first, especially if they are unfamiliar with the normal expectations and boundaries of intimate relationships. Instead, they may confuse pushing, threatening and similar behaviours as being signs of love and caring, signaling a deeper commitment to one another that is likely to have positive benefits in the long run [39].

Psychological, emotional, verbal abuse just like physical abuse encompasses a broad array of behaviours on dating violence. Such abuse may include insulting, criticizing, humiliating in front of friends, or berating a partner [28]. Examples of such threatening behaviors include threats to hurt a partner, threats to damage a partner's possessions, throwing objects at a partner, and starting but stopping short of hitting a partner. Psychological abuse includes emotional manipulation, for example, threatening suicide, ignoring the partner, or threatening to break up. Other common forms of such abuse are behaviours whose effect is to undermine the partner's self-esteem and independence, attempting to isolate a partner from family, friends, or other potential social supports, and attempting to make a victim feel "crazy" by continually questioning the person's judgment [58]. Besides psychological and physical abuse, the third major subtype of abuse between adolescent dating violence is sexual abuse. Sexual abuse between adolescent partners can involve rape, attempted rape, and other forms of sexual coercion, including birth-control sabotage [58]. Pressure to have sex before it is warranted or to have more sex than desired may also count as sexual [58]. The consequences of the violence have found gender differences with females reporting more negative emotional consequences of the violence including experiencing greater fear for their safety [31]. Boys were less likely than girls to perceive incidents of dating violence as physically or psychologically threatening or damaging.

Young adults who show a general tendency towards aggression or who use physical aggression against peers are also more likely to use aggression with a dating partner. Whereas some studies found this association for both males and females, another study found that general interpersonal aggression only predicted male use of dating aggression. Research shows that peer violence, such as fighting amongst peers or peer involvement in violent dating relationships, strongly predisposes adolescents to become involved in relationship violence [31]. When all these forms of violence are left unchecked, they could degenerate into mental and emotional health concern for adolescents. Post-traumatic stress disorder is developed following a traumatic and terrifying event such as sexual or physical assault. The threat of dating violence often continues after the abusive relationship has ended, in the form of stalking, harassment, and violent threats [47]. This kind of people who develop such, often have lasting and frightening thoughts and memories of the event and tend to be emotionally numb. However the individual may be experiencing fear, related to the partners behavior and pose a very real danger and can intimidate and incite distress, in the survivor.

Lasting effects of dating violence can be witnessed after a length of time and may roll on into the adult years depending on the magnitude and extent of abuse. A teen may carry on the violence into their adult relationships, either as a perpetrator or a victim. Perpetrators are more likely to continue with violence in their later years while victims are more likely to be involved in abusive relationships. This trend of behavioral events may persist throughout for very many years [53].

The effects of dating violence vary across the sexes. Girls are more likely to experience long term mental and behavioral problems like suicidal attempts, depression and substance abuse than boys [50]. Young men have the propensity to commit severe violence and endure lesser psychological consequences. On the other hand, young women have a tendency to be responsible for lesser violence and undergo more weighty psychological consequences. [25]. Boys involved in these forms of relationships are more aggressive and develop anti-social character traits. They are also more likely to damage property and turn to theft [49].

The words 'aggression' and 'violence' are often used interchangeably, yet they do not mean the same thing. 'Aggression' is something we can experience in situations that are physically or emotionally threatening to us. The 'fight or flight' reactions that we experience in such situations have a biochemical background and are closely related to the self-preservation instinct of most species, including humans. In anger-management training courses and programmes for violent offenders, it is advised that it is possible to exercise control over our aggressive potential. In a matter of seconds we can assess whether it is 'appropriate' to use violence in a certain situation or not. In developing a gender perspective on violence, many practitioners argue that violence is the decision to use one's aggressive potential to hurt another person's integrity.

To further explicate and elaborate on the definition of aggression and the actions associated with aggression, acts of aggression are generally classified into two categories; acts of aggression that are considered deliberative and controlled, versus acts of aggression that are more automatic and impulsive [10, 13, 8, 55]. Violence is inevitably linked to aggression, and human aggression is any behavior directed towards another individual that is carried out with the proximate (immediate) intent to cause harm. In addition, the perpetrator must believe that the behavior will harm the target, and that the target is motivated to avoid the behavior $[10,12,13,33]$. Violence is aggression that has extreme harm as its goal (e.g., death). Violence is considered aggressive, but in many instances, acts of aggression are not necessarily violent. For example, one child pushing another off a tricycle is an act of aggression but might not be considered an act of violence [10]. Researchers have described a wide range of developmental precursors to aggressive behavior, such as exposure to violence in familial environments or aggression from peers that appeared to prompt young adults to display 
specific aggressive behaviors in certain social situations [26[.

When women are exposed to mother-to-father violence, women's reports of physical aggression toward their partners increased, while men's exposure to father-to-mother violence appeared to be a significant risk factor for men's perpetration of DV [48]. Women who had experienced family violence may be more likely to become victims of partner violence $[17,27,42]$ reported that exposure to same-sex parents committing physical aggression toward an opposite-sex parent increased the risk of physical abuse perpetration towards a partner, though [46] found that women who were exposed to paternal-to-maternal IPV were three times more likely to perpetrate DV. In contrast, [36] found that college women who were exposed to childhood paternal IPV were at a greater risk of being physically victimized in dating relationships.

A common perception is that women are typically victims in abusive heterosexual relationships, while men are predominantly perpetrators. Correspondingly, the National Violence Against Women Survey (NVAWS) indicated that women were more likely to report physical, sexual, and power abuse/control from their partners, while men were more likely to report verbal abuse from their partners [22]. However, despite the perception that women are typically victims and that perpetrators tend to be males, research studies have shown that women, especially younger women, could be just as aggressive as men [38-41].

Lasting effects of dating violence can be witnessed after a length of time and may roll on into the adult years depending on the magnitude and extent of abuse. A teen may carry on the violence into their adult relationships, either as a perpetrator or a victim. Perpetrators are more likely to continue with violence in their later years while victims are more likely to be involved in abusive relationships. This trend of behavioral events may persist throughout for very many years [53].

The effects of dating violence vary across the sexes. Girls are more likely to experience long term mental and behavioral problems like suicidal attempts, depression and substance abuse than boys [49]. Young men have the propensity to commit severe violence and endure lesser psychological consequences. On the other hand, young women have a tendency to be responsible for lesser violence and undergo more weighty psychological consequences [25]. Boys involved in these forms of relationships are more aggressive and develop anti-social character traits. They are also more likely to damage property and turn to theft [49].

Dating violence is linked to the advancement and deterioration of mental health conditions. These conditions include: depression, post-traumatic stress disorder (PTSD), fretfulness, obsessive compulsive disorders, substance abuse and mental illnesses such as schizophrenia and bipolar disorders in adults [25]. "Victims are more likely to become depressed, perform worse in school, develop eating disorders, and are at higher risk for violent relationships in college compared to those who are never in violent teen relationships [67], those in abusive relationships can develop low self- esteem and dependency issues that will continue if not altered with corrective, healthy relationships."

A clinical psychologist [56], added in an email that in a short time period, girls can develop very low self-esteem. In the long-term, dating violence can lead to anxiety, depression, substance use, and other negative ways of coping with these feelings, "For example, girls with a history of violence are more likely to smoke, drink alcohol and use food to cope. So, mental and physical health is connected."

Certain early childhood experiences may predispose individuals to violent tendency in their romantic relationships as adolescents and adults. Adolescents who experienced greater family instability, maltreatment or social disadvantages tend to date at a younger age and experience dating violence at higher rates [68]. Young people who witness domestic violence in their family of origin are at a higher risk of inflicting violence upon later romantic partners although these findings have been somewhat inconsistent. This association appears to be stronger for male than for female. The witnessing of inter-parental violence plays a less significant role in becoming a victim of dating violence for both genders [51]. The family as a unit of care has a great effect in tackling adolescent problems. Family ties are severely tried during the period when an adolescent is presently $\mathrm{n}$ a relationship, and when adequate care is not taken to curtail the trend, emotional issues may arise in them. Families with adolescents can become closer, or conversely, more distant, when there are adolescent problems [58]. Some develop avoidant personality disorders, pervasive feelings of social inhibition and inadequacy, extreme sensitivity to negative evaluation. Mood disorders involve persistent feelings of sadness or periods of feeling overly happy or fluctuations from extreme happiness to extreme sadness [17]. Specifically mental health issues such as depressive symptoms and suicide attempt (suicidality), substance abuse, post-traumatic stress disorder (PTSD) and depression occurs more frequently as a result of dating.

Violent relationships can often be complex, and there are many kinds of abuse that can occur in a dating relationship: verbal, emotional, physical, and sexual. This abuse/violence can take a number of forms: sexual assault, sexual harassment, threats, physical violence, verbal, mental, or emotional abuse, social sabotage, and stalking. It can include psychological abuse, emotional blackmail, sexual abuse, physical abuse and psychological manipulation [23].

Dating violence crosses all racial, age, economic and social lines. The Center for Relationship Abuse Awareness describes dating abuse as a "pattern of abusive and coercive behaviors used to maintain power and control over a former or current intimate partner. The Family \& Community Development support group at citizen in Singapore has described what it calls tell-tale signs of an abusive [2].

Emotional abuse originates in the aggressor's desire to control the other person's behavior. The abuser tries to limit a dating partner's ability to act independently, and undermines their confidence. Verbal abuse can include swearing at a partner, insulting and belittling them, and threatening or 
terrorizing them with words. Typically, males use physical force to assert control, while females use it to protect themselves, to retaliate, or because they fear an assault. This type of abuse includes hair-pulling, biting, shoving, slapping, choking, strangling, punching, kicking, burning, using or threatening use of a weapon, and forcibly confining someone. Sexual abuse includes unwanted sexual touching, force or pressure to get a partner to consent, rape or attempted rape, and attempting or having sex with a person who is under the influence of alcohol or drugs [60].

\subsection{Gender Based Phenomenon of Dating Violence}

Gender-based violence is an umbrella term for any harm that is perpetrated against a person's will; that has a negative impact on the physical or psychological health, development, and identity of the person; and that is the result of gendered power inequities that exploit distinctions between males and females, among males, and among females. Although not exclusive to women and girls, GBV principally affects them across all cultures. Violence may be physical, sexual, psychological, economic, or sociocultural. Categories of perpetrators may include family members, community members, and those acting on behalf of or in proportion to the disregard of cultural, religious, state, or intra-state institutions. Moreover, Gender based violence (GBV) is an pandemic phenomenon which cuts across every society and geography even today. GBV can happen to men, women and children including sexual minorities, among which women remain more exposed and vulnerable. Right to freedom from violence is one of the basic human rights, but every day in hundreds of numbers across the world, most vulnerable and at risk population, include women and children, PLHIV, Transgender, differently able are deprived of this right. It is any kind of act that causes physical, psychological and emotional harm towards any person based on the gender of an individual. Gender and sexual violence is an offshoot of discriminatory practices and beliefs mainly influenced by patriarchy. It is driven by many factors operating in a range of social, cultural and economic contexts. One of the root causes is gender inequality in attitudes, behaviours and practices across societies and individuals encourage violence towards women and other vulnerable populations. Infact the cycle of violence is often described from the womb to tomb [61]

The common forms of abuse reported were shouting at a partner $(93 \%)$, slapping or pushing $(77 \%)$ and punching and kicking $(40 \%)$. It is however disturbing to note that many women do not know if they had been abused or not [3]. This could be due to the acceptance of some abusive behaviour as 'normal'. Reports in the print and electronic media reveal vicious attacks on women by intimate partners in different forms such as 'acid bath', rape, beatings, some of which sometimes result in the death of the victim. Many victims do not report for fear of reprisal from abusers or the belief that the police and the judicial system cannot help. The police are also reported to frequently dismiss complaints of domestic violence as a 'private matter' [4] in the study carried out in Abuja, Nigeria, a mother of one narrated her ordeal in the hands of her husband who constantly was hitting and beating her whenever he was drunk, and she lost two pregnancies as a result of his brutality. Also, in July 2014 [4] reported a case of 34 years old housewife, Mrs Fatima Bankole, who had her face stitched 26 times, after she got battered by her husband, Alhaji Kamoru Bankole for taking a piece of fish from the pot to break her fast. The CLEEN Foundation National Crime Victimization Survey, 2013, reported that 1 in every 3 respondents admitted to being a victim of dating violence. The survey also found a nationwide increase in dating violence in the past three years from 21 percent in 2011 to 30 percent in 2013.

Families from all social, racial economic, educational and religious backgrounds experience dating violence in different ways. In the United States of America, each year, women experience about 4.8 million intimate partners' related physical assaults and rapes while men are victims of about 2.9 million intimate partner related physical assaults. In parts of the third world generally and in West Africa, in particular, dating violence is prevalent and reportedly justified and condoned in some cultures. For instance, $56 \%$ of Indian women surveyed by an agency justified wife-beating on grounds like -bad cook, disrespectful to in-laws, producing more girls, leaving home without informing, among others.

Gender-based violence' (GBV) is still an emerging and developing term. Originally it was used mostly to replace the term '(male) violence against women', because the word woman refers to both individuals of the female sex and to feminine gender roles in society. Those developing the term wanted to emphasize that violence against women is a phenomenon that is related to the gender of both victim and perpetrator. Many definitions continue to focus solely on the fact that women are victims of violence: for example, the UNHCHR's CEDAW (Convention to Eliminate All Forms of Discrimination Against Women) committee states that GBV is "...violence that is directed against a woman because she is a woman or that affects women disproportionately". This table summarizes the issues addressed in the quotation above:

Table 1. Gender based violence.

\begin{tabular}{ll}
\hline & Action restricting a person's will or freedom \\
What? & Negative impact on physical or psychological health \\
& Negative impact on the identity of a person \\
Against whom? & Exploits distinctions between male and female, among males, and among females \\
& Everyone, but it affects mainly girls and women \\
How? & Violence may be: \\
& physical \\
\hline
\end{tabular}


psychological

economic

sociocultural

Everyone can. Common perpetrators may include:

Who does it?

family members

community members

those acting on behalf of cultural, religious, state, or intra-state institutions, or free to act because of their disregard

Perpetrators benefit in different ways when committing acts of violence. There are two main functions of genderbased violence:

In the case of women in general, gender-based violence is a way of assuring women's inferior position in society. Violence against women, and the threat of it, is a form of gender-based violence that deprives women of their rights socially before the law becomes involved. This is one of the reasons why long-standing laws on equality of the sexes, or general legal sanctions for most forms of violence against women, have not been able to end or even significantly limit the inequality of women and men by themselves [56].

In the case of LGBT (Lesbian, Gay, Bisexual and Transgendered) people and men who do not act according to dominant masculine gender roles, gender-based violence has the function of correction by example. The severity of the 'punishment' for men who do not act according to the demands of male gender roles (whether gay, bisexual or heterosexual) may be related to the perceived danger that their difference presents to normalized and dominant assumptions about gender. Their very lives might collide and appear to contradict the idea that there are natural forms of behaviour and social roles in general for men and women [66].

\subsection{Theoretical Framework}

The paper was based on the attachment theory. Attachment theory was developed by John Bowlby as an attempt to link human social and psychological behaviour. Bowlby developed a model that includes self-important; others and their shared relationships [15] posited an important part of healthy development was having a close and caring relationship with parents and other caregivers. Proximity to attachment figures helps infants to have increased chances of protection and survival from an evolutionary standpoint. In addition to the biological necessity of attachment, it is also satisfying for both the parents and the infant [16]. As the bonds strengthen between infant and parents, the infant begins to grow an inner representation of the parent, which develops "internal working models" of self, others, and selfother relationships [14]. The higher parental sensitivity and responsiveness are to the infant's needs, the more secure and healthy the attachment that develops. Infants begin to feel they are deserving of their parents' care-giving and that they have a secure base on which to rely in the future.

Parental insensitivity and unresponsiveness contribute to insecure attachment by the infant, leading the infant to internalize these experiences and find the world to be unsafe and rejecting, which makes forming relationships difficult and dangerous [6]. This experiment first separated infants from their parent, then exposed them to the presence of a stranger, and finally reunited them with their parent. The infant expressed proximity seeking behavior, a displayed desire or lack of desire for closeness, and the responses and behaviours were classified into patterns. Two dimensions were used to determine the infant's attachment behavior classifications, anxiety and avoidance. The degree of anxiety experienced from abandonment and the avoidance of closeness to the stranger contributed to the classification.

Based on observed patterns, Ainsworth divided infants into three categories: secure; two types of insecure, avoidant and anxious-ambivalent; and unclassifiable. Secure infants, who are low in avoidance and anxiety, showed signs of missing their parents upon leaving the room, greeted parents upon return, and used their parent as a secure base for exploring the room. Avoidant infants, who are high in avoidance and low in anxiety, explored the room without using their parents, showed little distress upon the parent leaving, and chose to play with toys over greeting their parents upon return. Anxious-ambivalent infants, who are low in avoidance and high in anxiety, did not explore the room, were distressed when their parents left the room, and were unable to be soothed upon their parents' return to the room. The unclassifiable type could not be placed in any of these categories until 1990, when Main and Solomon named the third type of insecurely attached infants as disorganized/disoriented. These infants, found to be high in avoidance and high in anxiety, behaved with no intentional attachment strategy or intention, and it was hypothesized that these infants experienced the most interpersonal problems, such as childhood trauma, with their attachment figures.

This traditional approach to attachment theory analyzes the parent's responsiveness in determining the child's attachment, but others have also looked into the infant's role in the attachment relationship. A meta-analysis reviewed infant temperament as a predictor of insecure parent-infant attachment bonds [35]. The strength of this association was low, and while infant temperament may play a role, parental behaviors have a stronger impact on parent-infant attachment.

\section{Materials and Methods}

The study used a descriptive research design. The population for this study comprised all Undergraduate students in University of Maiduguri, Borno State, Nigeria. The total population of Undergraduate students in the twelve Faculties of University of Maiduguri was 32,760 (thirty two thousand seven hundred and sixty), from which a sample of 384 (three hundred and eighty four) was drawn. [44] 
Simple random sampling technique was employed to select four faculties out of the twelve faculties in the University of Maiduguri. This was followed, by sampling of convenience to draw 384 (three hundred and eighty four) respondents from four faculties and they were as follows faculty of Education, Arts, Sciences, and Social sciences. There after 96 respondents were sampled from each faculty using sample of convenience. Sample of convenience was preferred to enable the researcher selects young students who are in part one and part two because they are not well grounded with the rules and regulations of the university, on like the higher level students who are more experienced with the school regulation. This paper used structured questionnaire to collect data from the respondents. Three hundred and eighty-four (384) copies of questionnaires were administered but three hundred and fifty-six (356) copies were retrieved, making $93 \%$ return rate. The paper employed both descriptive and inferential statistics. The analysis of the data collected was done using descriptive statistics (charts, frequency counts and percentages). The results were presented in tables and discussed according to the objectives.

\section{Result and Discussion}

Research Question 1: What are the types of dating violence?

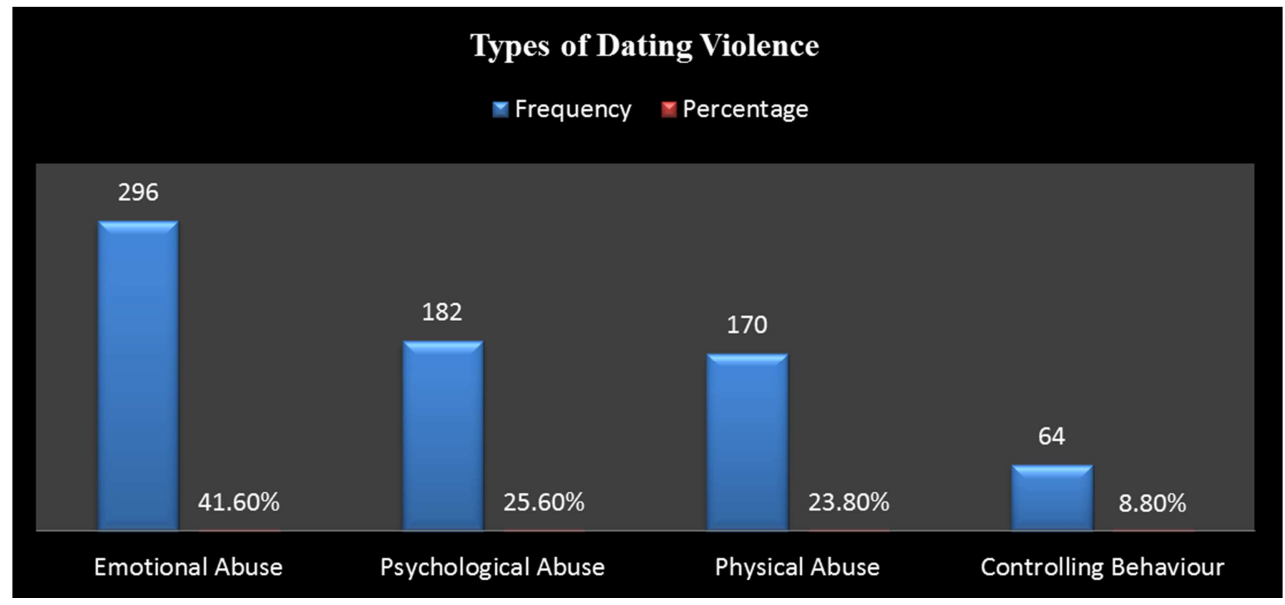

Figure 1. Types of Dating Violence.

Figure 1 shows the types of dating violence among undergraduate students in University of Maiduguri. Emotional abuse recorded 41.6\%, psychological abuse recorded $25.6 \%$, physical abuse recorded $23.8 \%$ and controlling behavior recorded $8.8 \%$. It can be deduced that emotional abuse was more pronounce $(41.6 \%)$ in the study area. This result revealed emotional abuse, psychological abuse, physical abuse and controlling behavior were the types of dating violence in the study area. This finding supports a study carried out to examine three aspects of IPV: emotional abuse, sexual coercion, and stalking/obsessive behavior. For emotional abuse, prevalence rates were high, averaging around $80 \% ; 40 \%$ of women and $32 \%$ of men reported expressive aggression, and $41 \%$ of women and $43 \%$ of men reported coercive control. Furthermore, new findings from the National Intimate Partner \& Sexual Violence Survey (NISVS) found that approximately half of Americans reported experiencing lifetime emotional abuse by a partner. Psychological aggression was measured by combining questions based on both expressive aggression (e.g. name calling) and coercive control (e.g. isolation tactics or threats of harm). Psychological aggression by an intimate partner was reported by $48.4 \%$ of women and $48.8 \%$ of men. Consequently, emotional abuse appears to be the most common form of IPV.

Research Question 2: What is the gender prompting involved in dating violence?

Table 2. Gender Prompting involved in Dating Violence.

\begin{tabular}{|c|c|c|c|c|c|}
\hline $\mathbf{S} / \mathbf{N}$ & Statement & SA & $\mathbf{A}$ & DA & SDA \\
\hline 1. & Your friend ridicules or insults women/men as a group & $128(36.0 \%)$ & $176(49.4 \%)$ & $38(10.7 \%)$ & $14(3.9 \%)$ \\
\hline 2. & Your friend mocks women/men in general & $96(27.0 \%)$ & $184(51.7 \%)$ & $52(14.6 \%)$ & $24(6.7 \%)$ \\
\hline 3 & $\begin{array}{l}\text { Your friend believes that the opposite sex is inferior, and says that women should } \\
\text { obey men (or Vice-versa) }\end{array}$ & $66(18.5 \%)$ & $202(56.7 \%)$ & $72(20.2 \%)$ & $16(4.5 \%)$ \\
\hline 4. & Your friend makes fun of you or discredit you as a women/man & 130( & 172 & $28(7.9 \%)$ & $26(37.3 \%)$ \\
\hline 5. & Your friend feels unjustly, criticizing your sexuality & $98(27.5 \%)$ & $208(58.4 \%)$ & $42(18.4 \%)$ & $8(2.2 \%)$ \\
\hline
\end{tabular}

Source: Field Survey, 2018

Table 2 shows the gender prompting involved in dating violence in the study area. From item one above, 36.0\% strongly agreed, $49.4 \%$ agreed, while $10.7 \%$ disagreed and
$3.8 \%$ strongly disagreed with the research statement. One can infer that ridiculing or insulting women/men as a group by one's friend is one of the socio-cognitive factors associated 
with dating violence. Item two above show that, $(27.0 \%)$ and $(51.7 \%)$ of the respondents strongly agreed and agreed respectively with the statement, while $14.6 \%$ and $6.7 \%$ disagreed and strongly disagreed respectively with the statement. One can conclude that mocking women/men by one's friend is one of the socio-cognitive factors associated with dating violence. From item three above, 18.5\% strongly agreed, $56.7 \%$ agreed, while $20.2 \%$ disagreed and $4.5 \%$ strongly disagreed with the research statement respectively. One can infer that believing that that the opposite sex is inferior by one's friend is one of the socio-cognitive factors associated with dating violence. Item four above show that, $(36.5 \%)$ and $(48.3 \%)$ of the respondents strongly agreed and agreed respectively with the statement, while $7.9 \%$ and $37.3 \%$ disagreed and strongly disagreed respectively with the statement. One can conclude that making fun of one by one's friend is one of the socio-cognitive factors associated with dating violence. From item five above, $27.5 \%$ strongly agreed, $58.4 \%$ agreed, while $18.4 \%$ disagreed and $2.2 \%$ strongly disagreed with the research question. This result revealed ridiculing or insulting women/men as a group, mocking women/men in general, believes that the opposite sex is inferior, making fun of one or discredit one as a women/man and unjustly, criticizing one sexuality by one's friends were the gender prompting involved in dating violence among undergraduate students of university of Maiduguri Borno state. This finding aligns with a study conducted by [4] in the study carried out in Abuja, Nigeria, a mother of one narrated her ordeal in the hands of her husband who constantly was hitting and beating her whenever he was drunk, and she lost two pregnancies as a result of his brutality.

\section{Conclusion}

Based on the findings within the limitation of this study, it was concluded that there was a significant relationship between detachment and dating violence among undergraduate students of university of Maiduguri Borno State. Therefore, understanding the types of dating violence is an important piece to working as a competent and effective educator. Certain types of dating violence such as psychological abuse may be more difficult to identify as the symptoms and effects are not externally visible. Therefore, it is important to be aware of the predictors and risk factors associated with dating violence to assist in determining if dating violence is present. Awareness of either a history of student maltreatment or early exposure to violence is essential as both are possible predicative factors of dating violence. The study suggests it is important to recognize these warning signs because it not only added to previous research on examining predictors of dating violence, but identified the role and risk that trauma symptoms have in the possibility of dating violence to occur in adolescent relationships. It is imperative to be aware of how trauma symptoms present in adolescents to be able to identify and screen for this predictive factor.

\section{Recommendations}

Based on research, the following recommendations are presented to assist educators and other professionals in the field to be competent and effective helpers in dealing with teen dating violence.

1. The Safe Dates program targeted to 100 and 200 levels, which reflects the suggested levels and age at which dating violence programs should be implemented by the Management of University of Maiduguri.

2. Safe date's program should be added to preexisting curriculum to educate undergraduate students about the effect of dating violence.

\section{References}

[1] Adamo. (2014). Structural Equation Modeling with Amos. Ottawa: Routledge.

[2] Adams AE, Sullivan CM, Bybee D, Greeson M. (2008). Development of the scale of economic abuse. Violence Against Women.14:563-588.

[3] AfrolNews, (2007). Sex differences in aggression in realworld settings: A meta-analytic review. Review of General Psychology.7:211-312.

[4] Agbo \& Choji (2014). The roles of coping and social support in battered women'smental health. Violence Against Women.9:212-421.

[5] Aguilar \& Nightingale, (1994). When men batter women: New insights into ending dating violence. New York: Simon \& Schuster.

[6] Ainsworth (1978). The prevalence of female-to-male intimate partner violence in an urban emergency department. Journal of Emergency Medicine. 2(1):232-314.

[7] Ajuwon, Funmilayo \& Osungbade (2011). Project SAFE: Domestic violence education for practicing physicians Women's Health Issues.143-177.

[8] Aluede. (2011). Single mothers, poverty, and depression. Psychological Medicine.27:21.

[9] Aminini-Philips, (2013). Prevalence of partner abuse: Rates of emotional abuse and control. Partner Abuse. 6(4):211-323.

[10] Anderson\& Bushman, (2002). Redefining intimate partner violence: Women's experiences with physical violence and non-physical abuse by age. International Journal of Sociology and Social Policy.32:131-176.

[11] Banks. (2007). Comparisons of intimate partner violence among partners in same- sex and opposite-sex relationships in the United States. American Journal of Public Health.92:2162-4274.

[12] Baron \& Richardson, (1994). Family dynamics: An essay on conflict and power. In: Sussman MB, Steinmetz SK, Peterson $\mathrm{G}$, editors. Handbook of marriage and the family. 2. New York: Plenum. pp. 121-754.

[13] Berkowitz, (1993). The prevalence of female-to-male intimate partner violence in an urban emergency department. Journal of Emergency Medicine. 27(3):171-214. 
[14] Bowlby, J. (1973). Attachment and loss, Vol. 2: Separation. New York: Basic Books.

[15] Bowlby, J. (1979). Attachment and loss, Vol. 2: Separation. New York: Basic Books.

[16] Bretherton, (1992). Women's experience of emotional abuse in intimate relationships: A qualitative study. Journal of Emotional Abuse. 6(2):39-71.

[17] Campbell JC. (2002). Health consequences of intimate partner violence. Lancet; 359:1331 1336.

[18] Caprara, Perugini, \& Barbaranelli, (1994). Beyond the c measurement trap: A reconstructed conceptualization and measurement of battered women. Psychology of Women Quarterly. 25:147 189.

[19] Carr \& VanDeusen. (2002). Intimate partner abuse and mental health: The role of social support and other protective factors. Violence Against Women; 8:720-745.

[20] Coker AL, Davis KE, Arias I, Desai S, Sanderson M, Brandt HM, Smith PH.( 2002). Physical and mental health effects of intimate partner violence for men and women. American Journal of Preventative Medicine.23:240-278.

[21] Coker AL, Derrick C, Lumpkin JL, Aldrich TE, Oldendick R. (2000b ). Help-seeking for Intimate partner violence and forced sex in South Carolina. American Journal of Preventative Medicine.19:316-20.

[22] Coker AL, McKeown RE, Sanderson M, Davis KE, Valois RF, Huebner ES. (2002 ). Severe dating violence and quality of life among South Carolina high school students. American Journal of Preventative Medicine.; 17:222-278.

[23] Copelon, (1994). Female victims of homicide: A portrait of their killers and the circumstances of their duties. Violence and Victims; 4:142-211.

[24] Cornelius, \& Bell, (2008). Harm to pets and the emotional abuse of women. Journal of Emotional Abuse. 8:61-80.

[25] Cutter-Wilson \& Richmond, (2011). Cumulative impact of sustained economic hardship on physical, cognitive, psychological, and social functioning. New England Journal of Medicine.312:1889-1671. [PubMed].

[26] Dodge, Coie, \& Lynam, (2006). Female perpetration of violence in heterosexual intimate relationships: Adolescence through adulthood. Trauma, Violence \& Abuse. 8:112-272.

[27] Doumas, Margolin, \& John, (1994). Gender and contextual factors in adolescent dating violence. Violence Against Women. 1998; 4:180-194.

[28] Draucker \& Martsolf, (2010). The roles of coping and social support in battered women's mental health. Violence Against Women. 10:245-378.

[29] Field \& Caetano, (2005). The emotionally abusive relationship: How to end abused and how to stop abusing. New Jersey: John Wiley \& Son.

[30] Foshee, Bauman, Linder, Rice, \& Wilcher (2007). Patriarchal terrorism and common couple violence: Two forms of violence against women. Journal of Marriage and the Family.61:234-285.

[31] Foshee, Reyes \& Ennett, (2010). Husbands' and wives' marital adjustment, verbal aggression, and physical aggression in early marriage. Journal of Consulting and Clinical Psychology. 2005; 73:28-37.

[32] Garcia-Moreno C, Jansen HA, Ellsberg M, Heise L, Watts CH. (2006). Prevalence of intimate partner violence: Findings from the WHO multi-country study on women's health and domestic violence. Lancet.368 (9543):1260-1269.

[33] Geen, (2001). Lethal and nonlethal violence against wives. Canadian Journal of Criminology.52:231-346.

[34] Gibb, Abramson, \& Alloy. (2004). Female victims of homicide: A portrait of their killers and the circumstances of their duties. Violence and Victims; 7:119-175.

[35] Goldsmith \& Alansky, (1987). The impact of different forms of psychological abuse on battered women. Violence and Victims. 15:102-127.

[36] Gover et al. (2008). Remaining in an abusive relationship: An investment model analysis of non voluntary commitment. Personality and Social Psychology Bulletin. 31:256-431.

[37] Hamberger LK. (2005). Men's and women's use of intimate partner violence in clinical samples: Toward a gender sensitive approach. Violence and Victims. 2(2):131-151.

[38] Harned M. (2001). Abused women or abused men? An examination of the context and outcomes of dating violence. Violence and Victims.16:269-285.

[39] Henton, Cate, Koval, Lloyd \& Christopher, (1993). Dangerous Domains: Violence Against Women in Canada. Scarborough, Ontario: International Thomas Publishing.

[40] Iconis, (2013). Relational aggression, gender, and socialpsychological adjustment. Child Development. 66:710-722.

[41] Jackson, (1999). A representative measure of psychological aggression and its severity. Violence and Victims. 21:26-48.

[42] Jankowski, Leitenberg, Henning, \& Coffey (1999). Testing a typology of batterers. Journal of Consulting and Clinical Psychology.72:538-711.

[43] Jezl, Molidor, \& White, (1996). Psychological factors in the longitudinal course of battering: When do couples split up? When does the abuse decrease? Violence and Victims.9:111372 .

[44] Krejcie, R. V., \& Morgan, D. W. (1970). Determining Sample Size for Research Activities. Educational and Psychological Measurement, 30, 607-610.

[45] Lewis \& Fremouw, (2001). Dating violence in the United States. Bureau of Justice Statistics.

[46] Luthra \& Gidycz (2006). Gender and family relationships. In: Sussman MB, Steinmetz SK, Peterson G, editors. Handbook of marriage and the family. 2. New York: Plenum. pp. 312 4177.

[47] Mechanic, Uhlmansiek, Weaver, \& Resick, (2000). Women's experience of emotional abuse in intimate relationships: A qualitative study. Journal of Emotional Abuse. 6(3):38-71.

[48] Milletich et al., (2010). Family Theories. Thousand Oaks, CA: Sage Publications.

[49] Mulford\& Giordano, (2008). Psychological abuse of women: Six distinct clusters. Journal of Family Violence.12(1):256211. 
[50] Murphy \& O’ Leary (1989). Nonphysical abuse among batterer program participants. Journal of Family Violence.16:213-323.

[51] O'Keefe, (2005). Psychological abuse in violent domestic relations. New York: Springer; 2001.

[52] Obi and Ozumba, (2007). Psychological abuse in violent domestic relations. New York: Springer; 2001.

[53] Offenhauer \& Buchalter, (2011). Emotional abuse. New York: Lexington Books.

[54] Ozumba, (2007). Age, period, and cohort effects on intimate partner violence. Violence and Victims. 2009; 24:627-638.

[55] Richetin \& Richardson, (2008). Women's experiences with battering: A conceptualization from qualitative research. Women's Health Issues. 7:142-192.

[56] Sheela Raja, (2008). Victimization in chronic fatigue syndrome and fibromyalgia In tertiary care: A controlled study on prevalence and characteristics. Psychosomatics.2:2338 .

[57] Shepherd MF, Campbell JA. The Abusive Behavior Inventory: A Measure of psychological and physical abuse. Journal of Interpersonal Violence. 1992; 7(3):291-305.

[58] Smith \& Donnelly, (2001). Measuring battering: Development of the women's experience with battering (WEB) scale. Women's Health. 2(5):281-321.

[59] Straus MA. (2004). Prevalence of violence against dating partners by male and female university students worldwide. Violence Against Women.10:790-811.
[60] Straus MA. (2005) Women's violence toward men is a serious social problem. In: Loseke DR, Gelles RJ, Cavanaugh MM, editors. Current controversies on family violence. 2. Newbury Park: Sage Publications. pp. 55-77.

[61] Straus, Ramirez, (2007). The revised Conflict Tactics Scales (CTS2) Journal of Family Issues.12:211-411.

[62] Sugarman \& Hotaling. (1989). The impact of different forms of psychological abuse on battered women. Violence and Victims. 13:103-118.

[63] Taft et al., (2009). Relational aggression, gender, and socialpsychological adjustment. Child Development. 67:612-832.

[64] Tan C, Basta J, Sullivan CM, Davidson WS. (1995). The longterm effects of battering on women's health. Women's Health: Research on Gender, Behavior, and Policy.4:41-70.

[65] Tjaden P, Thoennes N. (2000). Full report of the prevalence, incidence, and consequences of violence against women: Findings from the National Violence Against Women Survey (NCJ Report No 183781) Washington, DC: U.S. Department of Justice, Office of Justice Programs.

[66] Tolman RM. (1989). The development of a measure of psychological maltreatment of women by their male partners. Violence and Victims.4(3):159-177.

[67] Waterman (2002). Measuring intimate partner violence (IPV): You may only get what you ask for. Journal of Interpersonal Violence.2:341-532.

[68] Wekerle \& Wolfe, (1999). Psychological abuse in violent domestic relations. New York: Springer. 